\title{
ASSUMPTIONS UNDERLYING QUANTITATIVE AND QUALITATIVE RESEARCH: Implications for Institutional Research
}

\author{
Russel S. Hathaway
}

For institutional researchers, the choice to use a quantitative or qualitative approach to research is dictated by time, money, resources, and staff. Frequently, the choice to use one or the other approach is made at the method level. Choices made at this level generally have rigor, but ignore the underlying philosophical assumptions structuring beliefs about methodology, knowledge, and reality. When choosing a method, institutional researchers also choose what they believe to be knowledge, reality, and the correct method to measure both. The purpose of this paper is to clarify and explore the assumptions underlying quantitative and qualitative research. The reason for highlighting the assumptions is to increase the general level of understanding and appreciation of epistemological issues in institutional research. Articulation of these assumptions should foster greater awareness of the appropriateness of different kinds of knowledge for different purposes.

There are few subjects that generate as much passion among scientists as arguments over method. (Shulman, 1981, p. 5)

Institutional researchers are continually involved with implementing research agendas for various campus constituencies. Institutional research offices provide important technical and informational support for central decision makers in higher education by engaging in research-oriented activities such as tracking enrollment patterns, surveying incoming students, documenting faculty workloads, and assessing staff job satisfaction. Research methods that institutional researchers employ range from basic quantitative statistical analyses to interviews and case studies (Bohannon, 1988; Bunda, 1991; Fetterman, 1991; Hinkle, McLaughlin, and Austin, 1988; Jennings and Young, 1988; Sherman and Webb, 1988; Tierney, 1991). Some institutional researchers advocate integrating quantitative and qualitative approaches to institutional research (Mar-

Russel S. Hathaway, 4216D School of Education Building, The University of Michigan, Ann Arbor, Ml 48109-1259. 
shall, Lincoln, and Austin, 1991; Peterson, 1985a). Often, the driving forces behind the choice of methods are time, money, resources, staff, and those requesting the study. The choice to use a quantitative approach (e.g., survey and statistical analysis of responses) versus a qualitative approach (e.g., transcription analysis of interviews) is generally decided at the level of methods. Although the choice of methods is often a difficult one, institutional researchers generally make the decision with relative ease, choosing the method that will garner the information they seek. However, they often make their decisions without giving much thought to the assumptions underlying research methods.

Over the past decade, educational researchers have been engaged in an ongoing polemic concerning quantitative and qualitative research. They have been arguing over philosophical commensurability,' the concern that qualitative research has been seen as a methodological variation of quantitative research, and whether researchers should combine quantitative and qualitative research methods when pursuing research interests (Donmoyer, 1985; Eisner, 1981, 1983; Firestone, 1987; Howe, 1985, 1988; Shulman, 1981).

Although the intricate details of this debate are not of paramount concern for institutional researchers, the general discourse over the fundamental philosophical grounds guiding research methods is relevant. Some of those involved in the debate argue that the choice to use a quantitative or qualitative research approach should not be made at the method level (Guba and Lincoln, 1981). ${ }^{2}$ This concern has direct relevance for those making methodological choices in an applied field such as institutional research. The decision to use quantitative or qualitative methods is replete with assumptions concerning the nature of knowledge and reality, how one understands knowledge and reality, and the process of acquiring knowledge and knowledge about reality. When one chooses a particular research approach, one makes certain assumptions concerning knowledge, reality, and the researcher's role. These assumptions shape the research endeavor, from the methodology employed to the type of questions asked.

When institutional researchers make the choice between quantitative or qualitative research methods, they tacitly assume a structure of knowledge, an understanding and perception of reality, and a researcher's role. The purpose of this paper is to clarify and explore the underlying assumptions contained within quantitative and qualitative research. It is important for institutional researchers to understand the philosophical grounding of the two approaches so that they may reflect on those assumptions while engaging in institutional research. In addition, understanding the philosophical grounding also highlights the strengths and weaknesses of both approaches. The reason for contrasting the two paradigms is to increase the general level of understanding and appreciation of epistemological issues in the institutional research profession. Articulation of the epistemological differences should foster greater awareness of the appropriateness of different kinds of knowledge for different purposes; it may 
thereby help legitimate the adoption of alternative and more appropriate knowledge-yielding paradigms in institutional research. It should also help reduce conflicts within the field by justifying and providing a basis for tolerance of diversity and multiplicity in research design.

Greater epistemological appreciation seems to be an essential prerequisite to developing an appropriate inquiry approach whereby researchers would explicitly select a mode of inquiry to fit the nature of the problematic situation under study, the state of knowledge, and their own skills, style, and purpose (Donmoyer, 1985; Smith, 1983a). In addition, appreciation of epistemological issues has implications for the evaluation of institutional research products. It leads to a belief that the quality of a piece of research is more critically indicated by the appropriateness of the paradigm selected than by the mere technical correctness of the methods used (Donmoyer, 1985; Eisner, 1981; Herriott and Firestone, 1983; Smith 1983a).

The debate that has been going on among educational researchers will be highlighted in brief, emphasizing the major points that have been raised by proponents of quantitative and qualitative research, as well as the arguments for those who advocate the combination of the two approaches. This debate will be used as a stepping stone into a discussion of the underlying philosophies of quantitative and qualitative research. An example program review will be used to describe how the two approaches might structure the program investigation and evaluation. This example is not meant to represent an ideal, or even typical, method of conducting a review, but rather to provide a vivid sense of the distinctions between the two approaches. Finally, differences between the paradigms will be identified and discussed followed by a conclusion highlighting implications for conducting inquiry in institutional research.

\section{DEBATES OVER DISCIPLINED INQUIRY}

\section{Early Debate}

The educational research community is engaged in a heated debate over quantitative and qualitative approaches to disciplined inquiry. The crux of the debate centers on the incommensurability of the underlying assumptions structuring the approaches (Donmoyer, 1985; Eisner, 1981; Firestone, 1987; Howe, 1985). ${ }^{3}$ This debate in educational research, however, followed a crisis in the social sciences concerning identical philosophical issues (Bernstein, 1976, 1983; Rabinow and Sullivan, 1987). Bernstein (1976) has provided one of the most comprehensive summaries of the history of the social science debates, as well as a rich description of the various research paradigms that were, and still are, being discussed.

The debate over quantitative and qualitative research arose out of the social and political unrest of the 1960 s during which the foundations of the social 
disciplines came under radical criticism (Bernstein, 1976; Rabinow and Sullivan, 1987). Bernstein argues that these critiques came at a time when the social disciplines had arrived at a tentative agreement on an empirical foundation where they could begin a stable expansion of the scientific knowledge of society. Critics argued, and continue to argue, that the foundations of the social sciences were replete with weakness; that what was believed to be objective scientific knowledge was a veiled form of ideology that supported the status quo (Bernstein, 1976; Gordon, Miller, and Rollock, 1990; Stanfield, 1985). Others argued that the social sciences did not provide the critical perspectives on what was happening in society, nor did they provide solutions to the problems they set out to solve (Bernstein, 1976). The belief that a rational, systematic study of societal problems would result in policies and programs that would address them was doubted (Bernstein, 1976).

As the social sciences began to experience profound criticism and self-doubt, newly discussed approaches arose to rescue social science research from the depths of angst. Bernstein (1976) argues that linguistic philosophical inquiries were used to challenge the epistemological foundations of the social sciences. Phenomenology and hermeneutics also became more welcome in social scientific circles. These disciplines, often characterized as soft and subjective by empirical researchers, were perceived as panaceas for the ills facing social research (Bernstein, 1976). Advocates of phenomenology and hermeneutics believed that these approaches could provide elucidative insight into social processes that was not being acquired with empirical inquiry methods (Bernstein, 1976).

The literature produced in this period concerning the nature of research can best be described as muddled. Bernstein (1976) reports that there was no agreement during the 1960s and 1970s about what were provable results, what were the proper research methods, what were important problems to address, or what were "the most promising theoretical approaches" in the study of social science. It was during this confusing period that the educational community began questioning its approaches to disciplined inquiry. ${ }^{4}$

\section{Educational Debate}

Closely following what could be called the "angst" period in social science research, the educational research community began to experience a similar debate, beginning in the late 1970s and continuing today (Donmoyer, 1985; Eisner, 1981, 1983; Firestone, 1987; Garrison, 1986; Giarelli and Chambliss, 1988; Howe, 1985, 1988; Hutchinson, 1988; Lincoln and Guba, 1985; Marshall, Lincoln, and Austin, 1991; Sherman and Webb, 1988). Throughout this period, educational researchers have engaged in a heated debate over the degret to which quantitative and qualitative methods can be combined. This discours 
revolved around defining different facets of qualitative and quantitative research along with the debate focusing on the pros and cons of combining the two approaches. In general, researchers fall into three perspectives in this discussion: the purists, the situationalists, and the pragmatists (Rossman and Wilson, 1985). The purists would not entertain the notion of discussing combining the two approaches. Educational researchers within this perspective focus on the incommensurability between the two approaches and argue that the philosophies grounding the two approaches are so divergent in terms of assumptions about the world, truth, and reality that one should not even consider combining quantitative and qualitative research (Guba, 1987; Smith, 1983a, 1983b; Smith and Heshusius, 1986). The concern is that by combining approaches, researchers neglect to acknowledge that the different approaches make vastly different assumptions concerning knowledge and reality. Others have discussed the problems involved in ignoring the issue of underlying assumptions and focusing only on the benefits of combining both approaches (Donmoyer, 1985).

In contrast, those falling within the situationalist perspective focus on the level of method and argue "that certain methods are most appropriate for specific situations" (Rossman and Wilson, 1985, p. 630). The choice of method for the situationalist is partially determined by the questions to be answered. Furthermore, situationalist researchers also alternate between qualitative and quantitative methods as they engage the research process (Rossman and Wilson, 1985). In other words, researchers adhering to this perspective may use a survey to generate information that could assist in the development of an interview protocol.

For the pragmatist, quantitative and qualitative methods are viewed as capabie of informing one another throughout the research process. In contrast to the situationalist, who alters between the two approaches, the pragmatist views the two approaches capable of simultaneously bringing to bear both of their strengths to answer a research question. Using interviews, surveys, questionnaires, and observation techniques within one study is as an example of a pragmatic approach to integrating or combining research methods.

\section{Institutional Research Debate}

Throughout the past decade of discussion, the educational research debate has highlighted many of the strengths and weaknesses of quantitative and qualitative research, and it has brought to light the philosophies underlying the two approaches. For institutional researchers, the debate follows closely on the heels of the evolution of the profession, a profession that has slowly moved from engaging primarily in descriptive quantitative studies in the 1970s and 1980s (Peterson, 1985a, 1985b) to more multimethod studies in the 1990s (Peterson and Spencer, 1993). Institutional researchers have engaged in debates similar to 
those of educational researchers, but not to the same extent. Institutional researchers have primarily discussed quantitative and qualitative differences at the method level (Bohannon, 1988; Fetterman, 1991; Fincher, 1985; Hinkle, McLaughlin, and Austin, 1988; Jennings and Young, 1988; Marshall, Lincoln, and Austin, 1991; Tierney, 1991) and how different methodologies yield different information (Peterson and Spencer, 1993). At this level, institutional researchers have been attending, correctly so, to assumptions supporting specific statistical procedures (Bohannon, 1988; Yancey, 1988a, 1988b), such as having random selection when performing multiple regression, having a sample size larger than five in each cell of an ANOVA, or assuming a normal distribution. By attending to the assumptions at this level, institutional researchers have produced studies that have rigorous application of methods.

Institutional researchers advocating qualitative approaches have also appropriately focused attention on the assumptions guiding good qualitative research. Qualitative institutional researchers have tended to address data collection procedures, such as having an interview protocol composed of nonleading questions and accurate transcripts of observation or taped accounts (e.g., Miles and Huberman, 1984), but they fail to discuss or acknowledge the scientific philosophies (i.e., phenomenology, hermeneutics, positivism) in which they are grounded. Those using quantitative approaches also neglect to mention the philosophical grounds on which their approaches are based. It is important for institutional researchers to be cognizant of the philosophical assumptions guiding both quantitative and qualitative approaches. It is important not only because it is good practice, but because institutional research is an applied field in which much of what is done is used for policy decisions. These policy decisions, once implemented, make assumptions concerning the reality of campus life. These realities are defined, in part, by the underlying philosophies structuring the approach used by the institutional researcher. For example, a statistical analysis performed on survey results may describe certain aspects of the campus, but these aspects have been shaped by the people who developed the survey and may not reflect the reality as understood and experienced by those who answered the survey.

\section{PARADIGMS UNDERLYING QUANTITATIVE AND QUALITATIVE RESEARCH}

\section{Defining Paradigm}

A framework is needed to discuss the differences between philosophies underlying the quantitative and qualitative research approaches. The distinction between the philosophies can be made by using the concept of paradigm. The work of a number of philosophers (Bernstein, 1976; Firestone, 1987; Gubrium, 1988; Kuhn, 1962, 1970, 1974) is quite useful in defining the idea of a para- 
digm. Kuhn defines scientific paradigm as a theoretical framework, or a way of perceiving and understanding the world, that a group of scientists has adopted as their worldview. For Bernstein, the underlying paradigm dictates a level of generally unexamined common assumptions, attitudes, and expectations, and a framework within which inquiry operates. This paradigm guides a shared sense of what scientific inquiry is and could be the kind of reality being investigated, the proper form of inquiry, and a general orientation for perceiving and interpreting the world (Bernstein, 1976). The paradigm from which one operates has consequences for views of the nature of empirical knowledge, the relations of theory and practice, the relations of fact and perception, and the education and role of the theorist (Bernstein, 1976). When a scientist observes a phenomenon and interprets what this observation means, that scientist is using a particular paradigm to give that observation meaning. Gubrium (1988) defines paradigm as a way of structuring everyday experience, a way of framing events, a sense of what is real and how to prove it, and an implicit stance on ontology and epistemology (i.e., being and knowing). This paradigm also influences the methods chosen (Firestone, 1987) and implies policy and action (Banks, 1988).

In essence, scientific paradigms act as lenses through which scientists or researchers are able to perceive and understand the problems in their field and the scientific answers to those problems. Paradigms dictate what researchers consider data, what their role in the investigation will be, what they consider knowledge, how they view reality, and how they can access that reality. A scientific paradigm provides a group of scientists or researchers with a way of collectively making sense of their scientific world. It is this framework of everyday assumptions about knowledge, reality, and the proper methodology that will be summarized in the remainder of this paper.

\section{Distinguishing the Paradigms}

Quantitative and qualitative approaches can both serve research purposes, but in different ways and with different effects. The ways in which they are used and the insights provided are a function of the underlying assumptions of the paradigms grounding the approaches. The attempt here is to systematically articulate the paradigms underlying both these approaches by direct description and by contrast with a recognizable alternative. The two paradigms will be contrasted on a number of dimensions (summarized in Table 1).

Before discussing the differences between the two paradigms of inquiry, it may be useful to comment on the paradigms underlying the distinction between quantitative and qualitative research approaches. A review of the literature yields a wide array of distinctions between the philosophies undergirding the two approaches. ${ }^{5}$

Included among these are Geertz's (1973) distinction between thin and thick 
TABLE 1. The Paradigm Framework Underlying the Two Approaches

\begin{tabular}{|c|c|c|}
\hline & $\begin{array}{c}\text { Empirical-Analytic } \\
\text { (quantitative) }\end{array}$ & $\begin{array}{l}\text { Interpretive } \\
\text { (qualitative) }\end{array}$ \\
\hline Methodology & $\begin{array}{l}\text { Begin with hypothesis of a rela- } \\
\text { tionship between cause \& effect } \\
\text { (program \& outcome). } \\
\text { Test the hypothesis. } \\
\text { Develop instruments. } \\
\text { Identify sample (random). } \\
\text { Measure/code phenomenon. } \\
\text { Aggregate data. } \\
\text { Generalize: theory that has with- } \\
\text { stood this test. } \\
\text { Researcher should have objective } \\
\text { stance. }\end{array}$ & $\begin{array}{l}\text { Formulate a question. } \\
\text { Identify sample (purposive). } \\
\text { "Fix" phenomenon (interview, } \\
\text { observe, tape record). } \\
\text { Narrative articulation and inter- } \\
\text { pretation of themes. } \\
\text { Compare data types; integrate } \\
\text { material (as parts of a whole). } \\
\text { Hypothesis generating. } \\
\text { Write case descriptions. } \\
\text { Generalize? } \\
\text { Researcher should have participa- } \\
\text { tory stance. }\end{array}$ \\
\hline $\begin{array}{l}\text { Ontology } \\
\text { (Reality) }\end{array}$ & $\begin{array}{l}\text { Public events (e.g., discussion, } \\
\text { utterances, etc.) reflect a reality. } \\
\text { Private perceptions (e.g., beliefs, } \\
\text { perceptions, etc.). } \\
\text { Subjects and objects exist sepa- } \\
\text { rate from the perception of them. } \\
\text { Objective events, subjective } \\
\text { states. } \\
\text { Governed by laws. }\end{array}$ & $\begin{array}{l}\text { Public events. } \\
\text { People have different aims, atti- } \\
\text { tudes. } \\
\text { People interact within, and can } \\
\text { change, a local setting. } \\
\text { Subjects and objects located in } \\
\text { intersubjective communities. } \\
\text { Pcople construct and act within a } \\
\text { context which structures and con- } \\
\text { strains that activity. }\end{array}$ \\
\hline $\begin{array}{l}\text { Epistemology } \\
\text { (Knowledge) }\end{array}$ & $\begin{array}{l}\text { Knowledge = objective reports } \\
\text { of measured dimensions of the } \\
\text { phenomenon. } \\
\text { Compared against (tacit) norms } \\
\text { ("skills"). } \\
\text { Compared over time. } \\
\text { Differences/no differences attrib- } \\
\text { uted to hypothesized causal rela- } \\
\text { tionship, to lack of validity of } \\
\text { instruments, or to alternative } \\
\text { causes. } \\
\text { General statements of regularities } \\
\text { among objective properties that } \\
\text { are internally consistent and that } \\
\text { correspond to the way things } \\
\text { really are. }\end{array}$ & $\begin{array}{l}\text { Knowledge = understanding of } \\
\text { participants' aims, perspectives, } \\
\text { assumptions: the terms in which } \\
\text { their everyday life is grasped. } \\
\text { Plus articulation of the local so- } \\
\text { cial context of interaction. } \\
\text { Description of specific cases } \\
\text { (persons \& communities): people } \\
\text { employ interpretive schemes that } \\
\text { must be understood before action } \\
\text { can be described. } \\
\text { Character of the local context } \\
\text { must be articulated. }\end{array}$ \\
\hline
\end{tabular}


description; Hall's (1976) low context and high context; Pike's (1967) etic and emic; Kaplan's (1964) logic-in-use and reconstructed logic; Smith's (1983a) realist and idealist continuum; Smith and Heshusius's (1986) rationalist and naturalist distinction; Habermas's (1988) and Bernstein's (1976) empirical-analytic and interpretive distinction; and the distinctions between acquaintance with and knowledge about as variously construed by James (1918), Dewey (1933), Schutz (1967), and Merton (1972). For the purposes of this paper, the term empirical-analytic will be used to describe the paradigm structuring quantitative research, and the term interpretive will be used to describe the paradigm underlying qualitative research.

Most commonly, the empirical-analytic paradigm has been associated with positivism. There are many varieties of positivism (Phillips, 1983). Comptean positivism holds that the scientific method can be applied to human experiences (Phillips, 1983). Thus, researchers within the Comptean tradition focus upon observable, objectively determinable phenomena. In contrast, logical positivism is marked by an intense dislike of metaphysics and aims to remove the idea from both the natural and the human sciences (Phillips, 1983). Logical positivists also believe in the verifiability principle of meaning, which states that something is meaningful if and only if it is verifiable empirically-directly by observation through the senses. From the verifiability concept arose the idea of operational definitions (Phillips, 1983). Other terms used to describe this paradigm include hypothetico-deductive and objectivist (Moss, 1990).

The description of the interpretive inquiry paradigm has a wider range of descriptors. Interpretive inquiry can be described as phenomenological, hermeneutical, experiential, and dialectic. Naturalistic, inductive, and relativist are some of the other terms used to describe the interpretive paradigm (Moss, 1990). Each of these terms is difficult to describe in brief or with precision. It needs to be made clear that although many of these terms can be identified as interpretive research, caution is required from equating it with any one of them. This is due to the slight variation in assumptions concerning different interpretive approaches. ${ }^{6}$ As will be seen later, all the interpretive research traditions, however, generally share common assumptions about methodology, ontology, and epistemology.

\section{Methodological and Ontological Differences}

The description of the paradigms begins by comparing the researcher's role and relationship to the setting under the two paradigms, and by identifying the epistemological and validity assumptions underlying the choice of role and relationship. ${ }^{8}$ Knowledge and understanding of a college or university situation can be acquired in two ways: (1) by studying, "objectively," data generated by the situation, and (2) by becoming part of the situation by understanding participant 
views of it. We can come to "know" the chemistry and psychology departments by examining faculty research productivity, enrollment statistics, questionnaire results, or GRE subject tests; or, alternatively, by functioning within these departments for a period of time talking with faculty, students, and staff.

Empirical-analytic inquiry is characterized by the researcher's detachment from the organizational setting under study (Eisner, 1981; Phillips, 1983; Smith, 1983a, 1983b). The detachment derives, in part, from the assumption that the object under study is separate from, unrelated to, independent of, and unaffected by the researcher (Eisner, 1981; Smith, 1983a, 1983b). The mind is separate from reality (Smith, 1983a, 1983b) and truth is defined as a correspondence between our words and that independently existing reality (Smith and Heshusius, 1986). In other words, "there are social facts with an objective reality apart from the beliefs of individuals" (Firestone, 1987, p. 16). Physics provides an ideal example. The objects of interest are measured with instruments, the data are analyzed to determine if logical patterns seem to exist, and rational theories are constructed to integrate, explain, and perhaps predict a multitude of facts. Underlying the detachment of the researcher inquiring from an empirical-analytic perspective are critical ontological assumptions: the researcher is guided by belief in an external reality constituted of facts that are structured in a law-like manner (Firestone, 1987). In essence, researchers conducting inquiries within this paradigm are hoping to document laws that structure reality.

In contrast, inquiry for the interpretive paradigm carries with it the assumptions that the researcher can best come to know the reality of a situation by being there: by becoming immersed in the stream of events and activities, by becoming part of the phenomenon of study, and by documenting the understanding of the situation by those engaged in it (Firestone, 1987; Herriot and Firestone, 1983; Howe, 1985; Jacob, 1988; Smith, 1984). Jacob (1988) states, "Qualitative research has been characterized as emphasizing the importance of conducting research in a natural setting, as assuming the importance of understanding participants' perspectives, and as assuming that it is important for researchers subjectively and empathetically to know the perspectives of the participants" (p. 16). Knowledge is validated experientially (Firestone, 1987; Herriot and Firestone, 1983; Howe, 1985; Jacob, 1988; Smith, 1984). Underlying the interpretive paradigm is a very different set of epistemological assumptions from those of the empirical-analytic paradigm. Fundamental to the interpretive paradigm is the belief that knowledge comes from human experience, which is inherently continuous and nonlogical, and which may be symbolically representable (Firestone, 1987; Herriot and Firestone, 1983; Howe, 1985; Jacob, 1988; Smith, 1984). Reality is constructed by those participating in it, and understanding the reality experienced by the participants guides the interpretive researcher. Truth is "a matter of socially and historically conditioned agree- 
ment" (Smith and Heshusius, 1986, p. 6). An interpretive researcher would not look for the laws governing reality because, ultimately, reality is constructed and understood differently for each individual (Taylor, 1987). For example, an interpretive researcher could not describe the "objective" culture of an academic department, but could describe the culture as seen by those participating in it. Some would argue that one can never understand the reality of others, but only be able to articulate one interpretation of it (Cziko, 1989; Dilthey, 1990; Kent, 1991).

The researcher's role in empirical-analytic inquiry can be best described as that of onlooker. Since researchers operating from an empirical-analytic paradigm adhere to the concept of a mind-reality duality, researchers simply need to look around in the environment to document objective reality. Quantitative researchers are detached to avoid personal bias infringing on the description of reality (Firestone, 1987). Empirical-analytic research presupposes an independent reality and then investigates how we are a part of that reality and how we can know that reality (Firestone, 1987; Smith 1983a, 1983b; Smith and Heshusius, 1986). Subsequently, the researcher is a detached observer, looking at reality and attempting to understand its complexities and relationship to those doing the observation. The researcher may use a telescope, microscope, survey, or assessment instrument when viewing a selected piece of the world; such use allows the researcher to remain detached, an essential feature of empiricalanalytic inquiry. What the researcher sees (i.e., data, coded interviews) are taken prima facie as indicators of "reality."

For interpretive inquiry, the researcher becomes an actor in real situations." The researcher must attend to the total situation and integrate information from all directions simultaneously-interviews, observations, and collected cultural artifacts (Denzin, 1971; Herriot and Firestone, 1983; Howe, 1988; Smith, 1984; Taylor, 1987). The relevant world is the field surrounding the individual actor/ researcher (Denzin, 1971; Herriot and Firestone, 1983; Howe, 1988; Smith, 1984). Researchers engage what is being researched to understand what is taking place. They identify what they know about what they are studying to elucidate the understanding they are bringing to the situation (see e.g., McCracken, 1988; Rabinow and Sullivan, 1987). "It is by drawing on their understanding of how they themselves see and experience the world that they can supplement and interpret the data they generate" (McCracken, 1988, p. 12). The researcher's knowledge can be used as a guide, directing the researcher to possibilities and insights into that which is being researched (McCracken, 1988). For this reason, universal law and generalizability is limited because reality is a constructed concept and a researcher's interpretation is also a constructed part of the reality observed. Reality for those being studied is different for everyone in the researcher's field of vision.

Another difference between the two paradigms is the source of the analytical 
categories around which data are organized. In a typical piece of empiricalanalytic research, the investigator uses a theoretical framework from which to preselect a set of categories that will guide the inquiry (Firestone, 1987; Howe, 1985; Smith, 1983a, 1983b; Smith and Heshusius, 1986). The goal is to isolate and define categories precisely before the study is undertaken, and then to determine the relationships between them (Firestone, 1987; Howe, 1985; McCracken, 1988; Smith, 1983a, 1983b; Smith and Heshusius, 1986). Hypotheses are phrased in terms of these categories, and only those data pertaining to them are collected (Howe, 1985; McCracken, 1988). The life of a college or university microenvironment (i.e., academic department, student affairs office) is viewed through the lens of a limited number of categories. For example, when investigating the supervisory style of student affairs middle managers, an institutional researcher could apply categories of human development to see if these managers engage in situational supervision. At the extreme, some might argue that the reality being viewed is being actively structured by the categories employed by the researchers to investigate the phenomenon of interest.

Empirical-analytic researchers may derive their a priori categories from personal beliefs or experience, from theoretical formulation, or from their own or others' interpretive research (Heyl, 1975; McCracken, 1988). In the case of interpretive inquiry, there are, generally, no intentionally prescribed categories to constrain the researcher (Denzin, 1971; Eisner, 1981; Howe, 1988; Shulman, 1981; Smith, 1983a, 1983b). Instead, the interpretive researcher attempts to identify emergent themes within an understanding of the respondent's viewpoint of the context (Denzin, 1971; Eisner, 1981; Shulman, 1981; Smith, 1983). Features are noticed and identified through an interpretive, iterative process whereby data and categories emerge simultaneously with successive experience (McCracken, 1988). The process represents an experiential exploration and is particularly suited to early inquiry into new research territory (Denzin, 1971; Firestone, 1987; Smith and Heshusius, 1986). Interpretive inquiry is useful for generating tentative categories grounded in the concrete circumstance of a particular situation. Such emergent categories may subsequently be used as the a priori categories guiding the more deductive, hypothesis-testing empirical-analytic approach.

A caveat must be noted to the process just described. Some may argue that the idea of viewing a situation or phenomenon for "emergent" themes is unattainable. Phenomenologists and hermeneuticists might disagree with the description just provided. For them, a situation or occurrence cannot be comprehended without one's own knowledge about the situation. Everyone has some idea of the phenomenon at which they are looking and these ideas shape what is being seen. In other words, the "emergent" themes that are being observed may be seen because of the particular knowledge or ideas possessed by the researcher before the start of the research. Phenomenologists believe that the 
researcher's preknowledge can be identified and bracketed out when viewing a phenomenon (McCracken, 1988). In contrast, a hermeneuticist would disagree and argue that one can never remove one's own preknowledge from the investigation (Kvale, 1983; Packer and Addison, 1989). One cannot understand the situation without preknowledge, because preknowledge assists in understanding what is being seen.

A further difference is the aim of inquiry. The aim of inquiry for the empirical-analytic paradigm is to generalize from the particular to construct a set of theoretical statements that are universally applicable (Donmoyer, 1985; Firestone, 1987; Garrison, 1986; Howe, 1988; McCracken, 1988; Smith, 1983a, 1983b; Smith and Heshusius, 1986). The institutional research done in the empirical-analytic paradigm aims to develop understanding of classes of higher education phenomena, rather than to focus on particular instances in particular settings. Interpretive inquiry, however, is directed toward the unique situation or what Lewin (1951) calls a focus on the whole and the individual's present situation. The aim of interpretive inquiry is to describe in detail a specific situation or phenomenon under study. The situationally relevant products of qualitative inquiry serve both practical and theoretical purposes (Jacob, 1988; McCracken, 1988). They can provide guides for action in the immediate situation and ideas for developing hypotheses to guide quantitative inquiry (Miles and Huberman, 1984). ${ }^{10}$

\section{Epistemological Differences}

The different paradigms are also associated with different types of knowledge. The aim of situation relevancy pursued in interpretive research is served by knowledge of the particular phenomenon (i.e., college or university, academic department, etc.) under study (McCracken, 1988; Mishler, 1986). The aim of generalizability sought by empirical-analytic research is served by the development of universal knowledge. Interpretive inquiry focuses on the particular: the knowledge that is infused with human organization and human interest, as represented by the situation under study (Bernstein, 1976, 1983; McCracken, 1988; Mishler, 1986). For the interpretive paradigm, knowledge is knowledge only as understood within the social context in which it takes place (Guba, 1987; Guba and Lincoln, 1981; McCracken, 1988; Mishler, 1986; Smith, 1983a, 1983b; Smith and Heshusius, 1986). The meaning of a particular utterance or interaction can be understood and has meaning only within the specific context in which it occurred (McCracken, 1988; Mishler, 1986). In the extreme, generalizability within the empirical-analytic inquiry implies a dissociation of universal knowledge from human interest (Habermas, 1971). And, at the other extreme, qualitative inquiry implies a preoccupation with the idiosyncratic." 
Knowledge for both paradigms is further differentiated by what researchers consider to be data and the level at which they consider issues of meaning. In interpretive inquiry, the aim of understanding a particular situation requires that researchers make direct experiential contact with the phenomena under study (e.g., classroom, academic department, etc.). Understanding the events, activities, and utterances in a specific situation requires a complex appreciation of the overall context in which the phenomenon occurs (McCracken, 1988; Mishler, 1986). Context refers to the complete fabric of local culture, people, resources, purposes, earlier events, and future expectations that constitute timeand-space background of the immediate and particular situation (Denzin, 1971; Guba, 1987; Guba and Lincoln, 1981; McCracken, 1988; Mishler, 1986; Smith, 1984). Facts have no meaning in isolation from the setting (Herriott and Firestone, 1983; McCracken, 1988; Mishler, 1986). Meaning is developed from the point of view of the participant (Firestone, 1987; McCracken, 1988; Mishler, 1986; Smith, 1983a, 1983b). Interpretive research yields knowledge that is connected to the participant's definition or perspective of the situation, what Rogers (1951) has termed the "phenomenal field" of the person. Researchers involve themselves directly in the setting under study in order to appreciate organizational phenomena in light of the context in which they occur and from the participants' point of view.

In empirical-analytic inquiry, the aim of developing universal principles of institutional life necessitates stripping away the idiosyncrasies of the particular phenomenon studied to reveal what is generally applicable to all similar situations (Firestone, 1987; Garrison, 1986; Howe, 1985; Smith, 1983a, 1983b; Smith and Heshusius, 1986; Soltis, 1984). The separation of the universal from the particular is accomplished through several processes. With the aid of sampling, aggregation, and other analytic techniques, the uniqueness of individual academic departments or classrooms is randomized, controlled for, and otherwise "averaged," revealing the core of presumed common truths. The validity of such efforts relies on the comparability of measurements across observations, settings, and times, as well as the completeness with which the observational procedures and situations are documented. Hence, the concern with instrumentation, specification, precision, and adherence to methodological assumptions (i.e., sampling is random, variables are normally distributed).

Empirical-analytic research is designed to be detached from, and independent of, a specific situation under study in a particular organization, academic department, or classroom. The researcher determines the frequencies of, and associations among, events with respect to a set of hypothesized categories and relationships (Firestone, 1987; Garrison, 1986; Howe, 1985; Smith, 1982a, 1983b; Smith and Heshusius, 1986; Soltis, 1984). Meaning is assigned to events on the basis of a priori analytic categories and explicit researcher-free procedures. The spectrum of a phenomenon is filtered through the researcher's 
preset categories; elements related to the categories are selected, coded as data, and simultaneously given meaning by the categories (Firestone, 1987; Garrison, 1986; Howe, 1985; Smith, 1983a, 1983b; Smith and Heshusius, 1986; Soltis, 1984). As a result, data are considered factual when they have the same meaning across situations and settings. That is, they are context-free.

\section{AN ACADEMIC PROGRAM REVIEW EXAMPLE}

To illustrate how the underlying philosophical grounds of the two paradigms shape an approach to an institutional research question, a hypothetical example of an academic program review is presented. The example developed focuses on an English department's interest in whether it has successfully implemented its new focus on critical thinking skills and what impact the focus has on various outcomes of interest, including faculty workload. The assumption behind the design is the belief that interactive and collaborative class discussion will facilitate critical thinking skills more so than the normal faculty lecture format. By engaging with their classmates over course-assigned texts, the department hopes that the students will reflect on their own perspectives and interpretations, but also be challenged to better articulate what they believe the texts to be saying. In addition, the department hopes that the increase in skills of articulation will translate into better writing and better academic performance in other writing-based classes as well as better job placement upon graduation.

Table 2 highlights some of the major differences between an empirical-analytic and an interpretive approach to this study. Comparing the aims of the study, one notices that empirical-analytic institutional researchers would look to document the implementation of classroom discussions. They would hypothesize prior to the study what they think would occur, for example, what "types" of interactions they would see. In this case, they would hypothesize that discussions would facilitate the writing skills of those students participating in the study and compare them to a group of students in a control group who were exposed to the traditional lecture format. They would want to describe changes that occur, whether they be the presence or absence of what they expected to occur. In contrast, interpretive researchers' intention would be to explain the content and the processes of the discussions occurring in the classroom with the discussion intervention. They want to document the understanding of the intervention from the participants' viewpoints and explicate any unpredicted and emergent themes.

The aims of the study are structured by the underlying assumptions guiding the paradigms. On the interpretive side, the assumption that reality is constructed directs the researchers to attempt to document how the participants understand and experience the critical thinking focus of the department and how faculty view the impact on their workload. In contrast, the empirical-ana- 
TABLE 2. Hypothetical Academic Program Review

\begin{tabular}{|c|c|c|}
\hline & $\begin{array}{c}\text { Empirical-Analytic } \\
\text { (quantitative) }\end{array}$ & $\begin{array}{l}\text { Interpretive } \\
\text { (qualitative) }\end{array}$ \\
\hline $\begin{array}{l}\text { Stated aims of } \\
\text { the study }\end{array}$ & $\begin{array}{l}\text { To document implementation of } \\
\text { critical thinking component. } \\
\text { To chronicle (presence or ab- } \\
\text { sence of predicted) changes } \\
\text { Summative evaluation (decision } \\
\text { making and accountability). }\end{array}$ & $\begin{array}{l}\text { Explanation of participant and } \\
\text { processes of discussion. } \\
\text { Document understanding of } \\
\text { goals from participant perspec- } \\
\text { tives. } \\
\text { To articulate unpredicted, emer- } \\
\text { gent themes. } \\
\text { Formative evaluation (program } \\
\text { improvement). }\end{array}$ \\
\hline Design details & $\begin{array}{l}\text { Observation of classes for } 3 \\
\text { months. } \\
\text { Interviews with } 6 \text { faculty. } \\
\text { Surveys of faculty, students, and } \\
\text { graduates. } \\
3 \text { focus group discussions. }\end{array}$ & $\begin{array}{l}\text { Observation, interviews, field } \\
\text { notes in } 3 \text { classes-selected to } \\
\text { contrast for } 12 \text { months. } \\
\text { Interviews with } 6 \text { faculty, } 6 \text { stu- } \\
\text { dents, } 6 \text { graduates. } \\
3 \text { focus group discussions. }\end{array}$ \\
\hline $\begin{array}{l}\text { Material } \\
\text { obtained }\end{array}$ & $\begin{array}{l}\text { Observation notes of conversa- } \\
\text { tion "gist." } \\
\text { Coded for "indicators" of goal } \\
\text { attainment (a priori categories). } \\
\text { Multiple-choice survey questions } \\
\text { (a priori categories). } \\
\text { Course grades. }\end{array}$ & $\begin{array}{l}\text { Transcripts of focus group dis- } \\
\text { cussions and interviews. }\end{array}$ \\
\hline $\begin{array}{l}\text { Form of the } \\
\text { analysis }\end{array}$ & $\begin{array}{l}\text { Statistical assessment of change } \\
\text { over time in coded observations, } \\
\text { collapsed over interview and } \\
\text { group discussions. } \\
\text { Statistical comparison of survey } \\
\text { responses. } \\
\text { Interviews taken at face value as } \\
\text { statement of beliefs, attitudes, } \\
\text { perceptions. } \\
\text { Documentation of faculty work- } \\
\text { load hours. }\end{array}$ & $\begin{array}{l}\text { Articulation of goals, aims, feel- } \\
\text { ings. } \\
\text { Unconscious, preexisting as- } \\
\text { sumptions. } \\
\text { Rule enforcement-encourage- } \\
\text { ment, modeling of goal-directed } \\
\text { behavior. } \\
\text { Creation of social contexts that } \\
\text { encourage goal-directed behav- } \\
\text { ior, safe atmosphere, sense of } \\
\text { purpose. } \\
\text { Discussion of how participants } \\
\text { "understand" the goals. }\end{array}$ \\
\hline Findings & $\begin{array}{l}\text { No observed differences among } \\
\text { faculty, staff, and students. } \\
\text { No significant difference in } \\
\text { course grades between critical } \\
\text { thinking and control groups. }\end{array}$ & $\begin{array}{l}\text { Goal-directed behavior is enacted } \\
\text { differently by different faculty, } \\
\text { staff, and students, due to preex- } \\
\text { isting assumptions about depart- } \\
\text { ment, and different focus of } \\
\text { attention. }\end{array}$ \\
\hline
\end{tabular}


TABLE 2. Continued

\begin{tabular}{|c|c|c|}
\hline & $\begin{array}{l}\text { Empirical-Analytic } \\
\text { (quantitative) }\end{array}$ & $\begin{array}{l}\text { Interpretive } \\
\text { (qualitative) }\end{array}$ \\
\hline & $\begin{array}{l}\text { Increase in faculty workload } \\
\text { hours. }\end{array}$ & $\begin{array}{l}\text { Change in type of preparation } \\
\text { and feedback given to students, } \\
\text { thereby altering faculty percep- } \\
\text { tions of workload. }\end{array}$ \\
\hline Norms & $\begin{array}{l}\text { "Indicators" of successful goal- } \\
\text { directed behavior are treated as } \\
\text { factual. } \\
\text { Normative findings: decrease in } \\
\text { faculty utterances in class discus- } \\
\text { sions, increase in participant-par- } \\
\text { ticipant interactions, number of } \\
\text { participants speaking, increase in } \\
\text { categories such as "substantive," } \\
\text { "probing-monitoring," "manage- } \\
\text { ment," etc. } \\
\text { Increase in faculty/student inter- } \\
\text { actions outside of class. }\end{array}$ & $\begin{array}{l}\text { Empirical evidence sought of } \\
\text { goal-directed behavior. } \\
\text { Normative findings: interpretive } \\
\text { authority based on persuasive } \\
\text { justification (use of evidence and } \\
\text { explanation; questioning), and a } \\
\text { sense that text is open to differ- } \\
\text { ent readings, vs. faculty as au- } \\
\text { thority and guide, with the sense } \\
\text { that there is a single text mean- } \\
\text { ing. }\end{array}$ \\
\hline
\end{tabular}

lytic researchers' assumption that there is a "true" reality would direct them to determine patterns of relationships among numerous variables (race, gender, previous English classes, as well as course grades, postgraduation job placement and performance) and critical thinking and generate laws explaining how the critical thinking is having an impact (e.g., documenting any increase or decrease in faculty workload hours). The interpretive researchers would resist generating explanations about how students are experiencing the component, arguing that each student and faculty member constructs a different understanding and, therefore, generalized explanations are not possible.

The two paradigms also have different design details. The goal of interpretive research is to get as close to describing the participants' understanding as possible. Observing three classes and interviewing a select few students, faculty, and graduates provides researchers with an opportunity to analyze transcripts in detail. Subsequently, they can compare transcript analysis (1) to see if the intervention was implemented the same way by faculty, (2) to document how the students and faculty understood the intervention, and (3) to document participant understanding of the impact of the critical thinking focus. In contrast, empirical-analytic researchers may observe five classes and code observation by a priori "indicators" of interactive/collaborative learning (i.e., coding certain types of interactions and comparing between classes). By approaching classroom observations in such a manner (i.e., a priori indicators), these qualitative 
methods (interviews) are being done from within empirical-analytic framework. This highlights the point that just doing an interview does not necessarily indicate one is engaged in qualitative (interpretive paradigm) research. It is the assumptions being made about methodology, ontology, and epistemology that determine whether the interview is truly qualitative. Faculty interviews would be coded the same way as well.

One of the major differences between the two approaches is the implementation of an assessment instrument. Within the empirical-analytic paradigm, the assessment instrument items would be constructed beforehand from the researchers' ideas of what is critical thinking and what they think should be important outcomes of the new component. For this example, the assessment would be a pretest and posttest comparing critical thinking skills between the critical thinking group and control group. Following the administration of the tests, the researchers could compare scores between the control and experimental groups. They then would compare the "critical thinking" group with a control group to document any statistically significant differences between the two groups on critical thinking.

As one can see from Table 2, the type of material obtained also differs. As mentioned previously, the interpretive approach would yield transcripts of class discussions and faculty interviews. For the empirical-analytic approach, we would get observation notes coded for indicators of interactive/collaborative leaning in addition to the survey and assessment instrument information.

The form of analysis is one main area of difference between the two approaches. Empirical-analytic researchers would perform statistical analyses comparing the assessment and survey scores of the control group with that of the critical thinking group. The faculty interviews would be taken at face value as a statement of the faculty members' beliefs, attitudes, and perceptions. In addition, a mean for specific codes could be calculated and correlations among other variables of interest could be attained, therefore indicating that the researchers were operating within the empirical-analytic paradigm. In contrast, interpretive researchers would analyze the classroom discussion tapes and attempt to articulate the goals, aims, and feelings of the participants. Interpretive researchers would look to identify preexisting assumptions on the part of the participants and document where they see adherence to the critical thinking component guidelines and where they see instances of interactive/collaborative discussion. An interpretive analysis would attempt to identify how the students and faculty understood the class discussion and the critical thinking emphasis.

For this hypothetical program review, let us say that there were no differences between the classes who engaged in the discussion experience and those who did not. In the empirical-analytic paradigm, this result would be indicated by no significant difference between the two groups on the assessment instrument. In addition, student grades in other writing-based courses were not signif- 
icantly different between the two groups and graduates. The interpretive researcher would note that the intervention was implemented differently by different faculty due to preexisting assumptions about the text and the intervention, and the focus within the intervention of each faculty member. The empiricalanalytic researcher would conclude that the critical thinking focus was not significantly improving upon what was already being done in the department whereas the qualitative researcher would conclude the focus was not implemented the way it was intended or that it was implemented differently depending on the faculty member involved and student perception of the department.

Finally, the norms adhered to are different between the two paradigms. For empirical-analytic researchers, the indicators for successful impact of the critical thinking focus are treated as factual. The evidence sought are indicators whereas interpretive researchers would look for empirical evidence (observations) of critical reflection and how critical reflection is "understood" by departmental participants. For this example, let us say that there were changes in the discussion dynamics over the course of the observation period. Empirical-analytic researchers would see a decrease in faculty comments over the three months of observations with a concomitant increase in student-student interactions. There is also a corresponding increase in different coding categories. On the other hand, interpretive researchers would notice that those assuming the authority during the discussion are the ones able to build more persuasive argument for their text interpretations. Interpretive researchers would note that the intervention was implemented in slightly different ways with one group assuming responsibility and believing the texts to be open to multiple interpretations. Other groups would believe the text has one meaning and would then rely on the faculty to guide them to that meaning.

Overall, therefore, empirical-analytic researchers may conclude that the critical thinking focus was not successful as indicated by the nonsignificant findings. In addition, they would see the increase in faculty workload and might conclude that the time invested in faculty is not translated into the hoped-for positive outcomes. In contrast, interpretive researchers would indicate that they found that different faculty articulated different understandings of the critical thinking focus, and therefore, implemented it differently. In addition, interpretive researchers would articulate faculty perceptions of how their workload hours changed in terms of quality, that they were not just spending more time, but that time entailed more intense preparation for class to ensure critical engagement during discussion, as well as more attention to the type of feedback given to students to facilitate their critical thinking skills.

\section{IMPLICATIONS FOR INSTITUTIONAL RESEARCH}

As in everyday life, institutional researchers need both modes of inquiry, both ways of knowing, and both kinds of knowledge to advance understanding 
of our specific college or university. Most social scientists and educational researchers have typically advocated the use of one or the other mode of inquiry. In contrast, institutional researchers tend to rely on empirical-analytic research more regularly (Peterson, 1985a, 1985b). The reasons for the preference for empirical-analytic research are elusive. Perhaps it stems from an artifact left over from the social sciences or that the interpretive paradigm has not yet been seen as a viable and useful tool for understanding colleges and universities. This artifact entails the drive for institutional researchers to have their work viewed as based on "true science." Despite the success and usefulness of empirical-analytic research in institutional research, its limitations for the social sciences-and institutional research-have become increasingly apparent and of concern recently (Donmoyer, 1985; Eisner, 1981, 1983; Firestone, 1987; Garrison, 1986; Giarelli and Chambliss, 1988; Howe, 1985, 1988; Hutchinson, 1988; Lincoln and Guba; 1985; Marshall, Lincoln, and Austin, 1991; Peterson and Spencer, 1993; Sherman and Webb, 1988). Empirical-analytic research systematically overlooks critical features that often render the results epistemologically limited (Guba, 1987; Guba and Lincoln, 1981). Such features include the definition of human action in specific settings, the actor's particular definition of his/her situation, the human interest of the actor, and the historical context of the situation. These issues are exemplified by the program review example described previously, particularly in reference to how the faculty and students understood the critical thinking focus. Each faculty member had different perceptions of the component, perceptions possibly influenced by institutional culture and climate. The empirical-analytic approach neglects this information. These shortcomings can be overcome by qualitative research techniques.

Interpretive research, however, may appear replete with subjectivism and be viewed by university administrators as having questionable precision, rigor, or credibility. It may be easier for an administrator to make a decision based on findings from a large sample rather than trust a description of five case studies or five in-depth interviews. University administrators need to make decisions on what they think is a "typical" or "average" case that holds true across various university environments or in particular departments. One cannot fault an administrator for being uncomfortable basing a policy decision on five or six well-described cases when an empirical-analytic approach (with accompanying large database) might provide a better opportunity to generalize. However, these shortcomings can be overcome by empirical-analytic research.

Institutional research is currently characterized by two broad approaches. One is based on the assumptions that there exists a true reality, whereas the other is based on the assumption that there is no true reality but a reality that is constructed by shared understandings of participants. Both are methodologically precise. One utilizes techniques that produce results generalizable across contexts, but neglects the reality of institutions; and the other provides 
the researcher with in-depth knowledge that often is not generalizable. Although educational researchers and social scientists have debated the merits of combining the approaches, for institutional researchers, using both approaches can only strengthen the rigor from which they approach their assigned tasks. However, as we have seen, the choice embodies not a simple decision between methodologies, but an understanding of the philosophical assumptions concerning reality, the role of the researcher, what is knowledge, and what are data. By using both approaches, institutional researchers can strengthen the results of their endeavors. Institutional researchers need to identify and refer to exemplars of good research-research that is both methodologically precise and grounded in understanding of the philosophical assumptions undergirding both approaches.

\section{Empirical-Analytic and Interpretive Research Used Together}

Institutional research studies require that both approaches be simultaneously pursued, either by different researchers or by a single researcher. Of course, it must be acknowledged that some questions are more amenable to being investigated by one approach, but using both enhances institutional researchers' ability to understand "what is going on." Each mode offers distinctive advantages, suggesting circumstances (type of problem, state of knowledge, unit of analysis, researchers' role and purpose) in which one may be more appropriate. Qualitative research is more useful for exploring institutional phenomena, articulating participants' understandings and perceptions, and generating tentative concepts and theories that directly pertain to particular environments (e.g., academic departments, specific residence halls). By yielding in-depth knowledge of particular situations, it also more directly serves practitioners' and administrators' needs. The policies and/or decisions based on this type of interpretive information may be more directly suited to the specifics of the milieu from which it was derived. Quantitative research is suited to theory testing and developing universal statements. It also provides a "general" picture of an institutional situation or academic department climate.

The choice of approach will depend on a number of factors. First, the choice will depend on the institutional researcher's personal training, cognitive style, and preference. Second, the choice will no doubt depend on those being researched. For example, some individuals may be particularly uncomfortable with the idea of being interviewed and others may not like being filmed so that their interactions with students can be analyzed. Third, the choice could also depend on the intended audience for the research. Some audiences may want a concise summary of findings more easily produced by empirical-analytic inquiry than in-depth articulations of subjects' realities. Fourth, the choice may depend on time and money-issues often on the minds of institutional re- 
searchers. Often, people assume that qualitative research involves a larger investment of time. In reality, the time needs for both quantitative and qualitative research may be close to equal, just distributed differently. For quantitative research, much of the time is spent developing surveys, distributing them, compiling the data, analyzing the data, and presenting the results. Interpretation of the results is a relatively small portion of the overall time spent on a quantitative study. On the other hand, the majority of time in qualitative research is spent on interpretation, analyzing pages of transcripts, viewing videotapes over and over, while the time spent on the collection of data is a relatively small portion of the overall time commitment. Finally, one cannot ignore the history of the institutional research office, what is the preferred research approach, and what those using the office prefer in terms of research. One cannot suddenly switch from quantitative to qualitative methods without checking the political ramifications of doing so.

In contrasting the two research approaches, the attempt has been to discuss the limitations associated with different ways of knowing. In light of these limitations, to continue the exclusive use of one approach that has characterized institutional research will produce limited results-that is, results that are methodologically rigorous but at times inappropriate. Institutional researchers' abilities to grasp the breadth, depth, and richness of college and university life are hampered by allegiance to a single mode of inquiry. Institutional researcher efforts to develop comprehensive pictures of college and university phenomena are handicapped when only one (either quantitative or qualitative) approach is advocated and practiced. We can survey regarding the benefits of a new departmental focus and find that the new approach is not increasing student performance on particular skills. We could find out that there is no improvement, but we will not know exactly why there is no improvement. A survey could point an institutional researcher to the problem, and in-depth interviews with some students could provide the information necessary to begin to explain the "no improvement" finding.

Institutional researchers can alternate between the two approaches. Peterson (1985a) advocates alternating between quantitative and qualitative research, using findings generated from one approach to generate research questions for the other. In the previous example, there was no significant improvement in skills following a new departmental focus. Using this information, an institutional researcher could interview students to see how they experienced the new focus. Through these interviews a researcher could identify common themes (e.g., students feel positive about the focus; however, it is not being implemented consistently) that could be used to generate questionnaire items for additional surveys. By alternating between the two modes, an institutional researcher could get a more accurate picture of the new departmental focus that may not have been possible using only one approach. 


\section{CONCLUSION}

A major reason why research methodology in institutional research is such an exciting area is that institutional research is not itself a discipline. Indeed, it is hard to describe institutional research. However, it is a field containing phenomena, events, institutions, problems, persons, and processes, which themselves constitute the raw material for inquiries of many kinds. Many of these inquiries provide the foundation from which to develop policies and institutional interventions.

Due to the complexity of institutional research, the choice of research approach to a question should not be taken lightly. Each approach to an institutional research problem or question brings its own unique perspective. Each sheds its own distinctive light on the situations and problems institutional researchers seek to understand (Peterson and Spencer, 1993). The issue is not choosing a qualitative or nonqualitative approach, but it is deciding how an institutional researcher approaches the world. Choosing an approach is not a decision between methods; each choice is replete with underlying assumptions about reality. Research methods are not merely different ways of achieving the same end. They carry with them different ways of asking questions and often different commitments to educational and social ideologies. The attempt here has been to clarify the distinction between the two approaches so that the two approaches are viewed as more than simply alternative methods.

As institutional researchers employ their crafts, they make a multitude of decisions concerning research methods. These decisions have a direct impact on how they make meaning and how reality is structured and understood by institutional researchers and their constituencies. In some ways, the choice of quantitative and qualitative approaches creates the reality we are attempting to discover. By making a choice between quantitative or qualitative inquiry, "to a significant extent, we choose our world view" (Allender, 1986, p. 188). For institutional researchers, it is not just a choice between "doing interviews" or "conducting a survey"; it is a choice between assumptions about the world.

\section{NOTES}

1. Definitions of some terms are in order here. Commensurability refers to the ability to compare philosophical underpinnings without a neutral frame of reference. Epistemology is the investigation or study of the origin, structure, methods, and validity of knowledge (Runes, 1983). Ontology is a theory as to what exists (Urmson and Ree, 1989) or the assumptions about existence underlying any conceptual scheme, theory, or system of ideas (Flew, 1984). Phenomenology is the study of how the world is experienced from the actor's/subject's own frame of reference (Patton, 1980). Hermeneutics is the art and science of interpreting the meaning of tcxis which stresses how prior understandings and prejudices shape the interpretive process (Runes, 1983). Dialectic refers to a process through which what is known emerges within an interaction between the knower and what is to be known. 
2. Please see Guba and Lincoln (1988) for an in depth treatment of the distinction between method and methodology.

3. Moss (1990) provides a brief and useful discussion about the distinction among the terms incompatible, incommensurable, and incomparable. The reader is directed to Moss's comments as well as to Bernstein's (1983) in-depth discussion concerning the definitions of these terms.

4. With the advent and development of critical theory and postmodernism, some (Lather, 1991a, 1991b) would argue that we are currently immersed in a crisis over what it means to do research. The reader is directed to Darder (1991), Giroux (1988), and Gore (1993) for descriptions of critical theory, and Bauman (1992), Giroux (1991), and Rosenau (1992) for descriptions of postmodernism.

5. For this paper, the distinction between the quantitative and qualitative paradigms is being used as a heuristic device. One must note, however, that this distinction may oversimplify the various philosophical differences even within the two paradigms.

6. To distinguish the different interpretive approaches is beyond the purview of this paper. The reader is directed to Denzin and Lincoln's (1994) Handbook of Qualitative Research and Lancy (1993) for in-depth explorations of the distinctions.

7. Firestone (1987) argues that the two paradigms can also be distinguished by differing rhetoric. In essence quantitative and qualitative methods "lend themselves to different kinds of rhetoric" (p. 16). Subsequently, each method type uses different presentation techniques and means of persuasion to express assumptions about methodology, ontology, and epistemology and to convince readers about conclusions.

8. For the sake of this paper, methodology, ontology, and epistemology have been separated for convenience and clarity. Generally, however, these concepts are so intertwined that discussing one almost necessitates discussing one or both of the other. For example, discussing what each paradigm believes to be "reality" (ontology) almost dictates what can be known (epistemology) about that reality and how that reality can be measured (methodology).

9. The degree of engagement varies depending on the qualitative approach being used. For example, nonparticipant observers are not actively involved in the situation whereas participant observers attempt to assume a role to understand the reality as constructed and comprehended by those in the situation.

10. Smith and Heshusius (1986) raise a common concern among many educational researchers that qualitative research should not be thought of as just a procedural variation of quantitative research. The reader should note this caveat when entertaining the notion of using qualitative data collection and analysis as an avenue from which to generate categories for quantitative research.

11. It would be misleading to imply that qualitative research is not concerned with generalizability. Firestone (1993) highlights the various arguments for, and the types of generalizability within, qualitative research, and Kirk and Miller (1986) discuss reliability and validity in qualitative research.

\section{REFERENCES}

Allender, J. S. (1986). Educational research: A personal and social process. Review of Educational Research 56(2): 173-193.

Banks, J. A. (1988). Multiethnic Education, 2nd ed. Boston: Allyn \& Bacon.

Bauman, Z. (1992). Intimations of Postmodernity. New York: Routledge.

Bernstein, R. J. (1976). The Restructuring of Social and Political Theory. Philadelphia: The University of Pennsylvania Press.

Bernstein, R. J. (1983). Beyond Objectivism and Relativism. Science, Hermeneutics, and Praxis. Philadelphia: The University of Pennsylvania Press. 
Bohannon, T. R. (1988). Applying regression analysis to problems in institutional research. In B. D. Yancey (ed.), Applying Statistics in Institutional Research, 43-60. San Francisco: Jossey-Bass, Publishers.

Bunda, M. A. (1991). Capturing the richness of student outcomes with qualitative techniques. In D. M. Fetterman (ed.), Using Qualitative Methods in Institutional Research, pp. 35-47. San Francisco: Jossey-Bass, Publishers.

Cziko, G. A. (1989). Unpredictability and indeterminism in human behavior: Arguments and implications for educational research. Educational Researcher 18(3): 17-25.

Darder, A. (1991). Culture and Power in the Classroom. A Critical Foundation for Bicultural Education. New York: Bergin \& Garvey.

Denzin, N. K. (1971). The logic of naturalistic inquiry. Social Forces 50: 166-182.

Denzin, N. K., and Y. S. Lincoln (1994) (eds.). Handbook of Qualitative Research. Thousand Oaks, CA: Sage Publications, Inc.

Dewey, J. (1933). How We Think. Massachusetts: D. C. Heath.

Dilthey, W. (1990). The rise of hermeneutics. In G. L. Ormiston and A. D. Schrift (eds.), The Hermeneutic Tradition. From Ast to Ricoeur (pp. 101-114). Albany: State University of New York Press.

Donmoyer, R. (1985). The rescue from relativism: Two failed attempts and an alternative strategy. Educational Researcher 14(10): 13-20.

Eisner, E. W. (1981). On the differences between scientific and artistic approaches to qualitative research. Educational Researcher 10(4): 5-9.

Eisner, E. W. (1983). Anastasia might still be alive, but the monarchy is dead. Educational Researcher 12(5): 13-14, 23-24.

Fetterman, D. M. (1991). Qualitative resource landmarks. In D. M. Fetterman (ed.), Using Qualitative Methods in Institutional Research, pp. 81-84. San Francisco: Jossey-Bass, Publishers.

Fincher, C. (1985). The art and science of institutional research. In M. W. Peterson and M. Corcoran (eds.), Institutional Research in Transition, pp. 17-37. New Directions for Institutional Research. San Francisco: Jossey-Bass Inc., Publishers.

Firestone, W. A. (1987). Meaning in method: The rhetoric of quantitative and qualitative research. Educational Researcher 16(7): 16-21.

Firestone, W. A. (1993). Alternative arguments for generalizing from data as applied to qualitative research. Educational Researcher 22(4): 16-23.

Flew, A. (1984). A Dictionary of Philosophy. London: The Macmillan Press Ltd.

Garrison, J. W. (1986). Some principles of postpositivistic philosophy of science. Educational Researcher 15(9): 12-18.

Geertz, C. (1973). The interpretation of Cultures. New York: Basic Books.

Giarelli, J. M., and Chambliss, J. J. (1988). Philosophy of education as qualitative inquiry. In R. R. Sherman and R. B. Webb (eds.), Qualitative Research in Education: Focus and Methods, pp. 30-43. New York: The Falmer Press.

Giroux, H. A. (1988). Schooling and the Struggle for Public Life. Critical Pedagogy in the Modern Age. Minneapolis, MN: University of Minnesota Press.

Giroux, H. A. (1991) (ed.). Postmodernism, Feminism, and Cultural Politics. Albany, NY: State University of New York Press.

Gordon, E. W., F. Miller, and D. Rollock (1990). Coping with communicentric bias in knowledge production in the social sciences. Educational Researcher 19(3): 14-19.

Gore, J. M. (1993). The Struggle for Pedagogies. Critical and Feminist Discourses as Regimes of Truth. New York: Routledge.

Guba, E. (1987). What have we learned about naturalistic evaluation? Evaluation Practice 8(1): 23-43. 
Guba, E., and Y. Lincoln (1981). Effective Evaluation. San Francisco: Jossey-Bass.

Guba, E. G., and Y. S. Lincoln (1988). Do inquiry paradigms imply inquiry methodologies? In D. M. Fetterman (ed.), Qualitative Approaches to Evaluation in Education: The Silent Scientific Revolution, pp. 89-115. New York: Praeger Publishers.

Gubrium, J. (1988). Analyzing Field Reality. Newbury Park, CA: Sage.

Habermas, J. (1971). Knowledge and Human Interest. Boston, MA: Beacon.

Habermas, J. (1988). On the Logic of the Social Sciences (S. W. Nicholsen and J. A. Stark, trans.). Cambridge, MA: The MIT Press.

Hall, E. T. (1976). Beyond Culture. New York: Doubleday.

Herriott, R. E., and W. A. Firestone (1983). Multisite qualitative policy research: Optimizing description and generalizability. Educational Researcher 12(2): 14-19.

Heyl, J. D. (1975). Paradigms in social science. Society 12(5): 61-67.

Hinkle, D. E., G. W. McLaughlin, and J. T. Austin (1988). Using log-linear models in higher education research. In B. D. Yancey (ed.), Applying statistics in Institutional Research, pp. 23-42. San Francisco: Jossey-Bass, Publishers.

Howe, K. R. (1985). Two dogmas of educational research. Educational Researcher 14(8): $10-18$.

Howe, K. R. (1988). Against the quantitative-qualitative incompatibility thesis or dogmas die hard. Educational Researcher 17(8): 10-16.

Hutchinson, S. A. (1988). Educational and grounded theory. In R. R. Sherman and R. B. Webb (eds.), Qualitative Research in Education: Focus and Methods, pp. 123-140. New York: The Falmer Press.

Jacob, E. (1988). Clarifying qualitative research: A focus on traditions. Educational Researcher (17(1): 16-24.

James, W. (1918). The Principles of Psychology. New York: Dover.

Jennings, L. W., and D. M. Young (1988). Forecasting methods for institutional research. In B. D. Yancey (ed.), Applying Statistics in Institutional Research, pp. 77-96. San Francisco: Jossey-Bass, Publishers.

Kaplan, A. (1964). The Conduct of Inquiry. San Francisco: Chandler.

Kent, T. (1991). On the very idea of a discourse community. College Composition and Communication 42(4): 425-445.

Kirk, J., and M. L. Miller (1986). Reliability and Validity in Qualitative Research. Beverly Hills, CA: Sage Publications, Inc.

Kuhn, T. S. (1962). The structure of Scientific Revolutions. Philadelphia: The University of Pennsylvania Press.

Kuhn, T. S. (1970). The Structure of Scientific Revolutions, 2nd ed. Chicago: University of Chicago Press.

Kuhn, T. S. (1974). Second thoughts on paradigms. Reprinted in The Essential Tension: Selected Studies in Scientific Tradition and Change. Chicago: University of Chicago Press.

Kvale, S. (1983). The qualitative research interview: A phenomenological and a hermeneutical mode of understanding. Journal of Phenomenological Psychology 14(2): 171-196.

Lancy, D. (1993). Qualitative Research in Education. New York: Longman.

Lather, P. 1991a). Getting Smart: Feminist Research and Pedagogy Within the Postmodern. New York: Routledge.

Lather, P. (1991b). Deconstructing/deconstructive inquiry: The politics of knowing and being known. Educational Theory 41(2): 153-173.

Lewin, K. (1951). Field Theory in Social Science. New York: Harper.

Lincoln, Y. S., and E. G. Guba (1985). Naturalistic Inquiry. Beverly Hills: Sage Publications. 
Marshall, C., Y. S. Lincoln, and A. E. Austin (1991). Integrating a qualitative and quantitative assessment of the quality of academic life: Political and logistical issues. In D. M. Fetterman (ed.), Using Qualitative Methods in Institutional Research, pp. 6580. San Francisco: Jossey-Bass, Publishers.

McCracken, G. (1988). The Long Interview. Newbury Park, CA: Sage Publications, Inc. Merton, R. (1972). Insiders and outsiders: A chapter in the sociology of knowledge. In Varieties of Political Expression in Sociology. Chicago: The University of Chicago Press.

Miles, M. B., and A. M. Huberman (1984). Drawing valid meaning from qualitative data: Toward a shared craft. Educational Researcher 13(5): 20-30.

Mishler, E. G. (1986). Research Interviewing. Context and Narrative. Cambridge, MA: Harvard University Press.

Moss, P. A. (1990, April). Multiple Triangulation in Impact Assessment: Setting the Context. Remarks prepared for oral presentation in P. LeMahieu (Chair), Multiple triangulation in impact assessment: The Pittsburgh discussion project experience. Symposium conducted at the annual meeting of the American Research Association, Boston, Massachusetts.

Packer, M. J., and R. B. Addison (1989). Introduction. In M. J. Packer and R. B. Addison (eds.), Entering the Circle: Hermeneutic Investigation in Psychology, pp. 13-36. Albany: State University of New York Press.

Patton, M. Q. (1980). Qualitative Evaluation Methods. Beverly Hills, CA: Sage Publications, Inc.

Peterson, M. W. (1985a). Emerging developments in postsecondary organization theory and research: Fragmentation or integration. Educational Researcher 14(3): 5-12.

Peterson, M. W. (1985b). Institutional research: An evolutionary perspective. In M. W. Peterson and M. Corcoran (eds.), Institutional Research in Transition, pp. 5-15. New Directions for Institutional Research, no. 46. San Francisco: Jossey-Bass Inc., Publishers.

Peterson, M. W., and M. G. Spencer (1993). Qualitative and quantitative approaches to academic culture: Do they tell us the same thing? Higher Education: Handbook of Theory and Research, Vol. IX, pp. 344-388. New York: Agathon Press.

Phillips, D. C. (1983). After the wake: Postpositivistic educational thought. Educational Researcher 12(5); 4-12.

Pike, K. L. (1967). Language in Relation to a Unified Theory of the Structure of Human Behavior. The Hague: Mouton.

Rabinow, P., and W. M. Sullivan (1987). The interpretive turn: A second look. In P. Rabinow and W. M. Sullivan (eds.), Interpretive Social Science. A Second Look, pp. 1-30. Berkeley, CA: University of California Press.

Rogers, C. R. (1951). Client-Centered Therapy. Boston: Houghton.

Rosenau, P. M. (1992). Post-Modernism and the Social Sciences: Insights, Inroads, and Intrusions. Princeton, NJ: Princeton University Press.

Rossman, G. B., and B. L. Wilson (1985). Numbers and words. Combining quantitative and qualitative methods in a single large-scale evaluation study. Evaluation Review $9(5): 627-643$.

Runes, D. D. (1983). Dictionary of Philosophy. New York: Philosophical Library, Inc.

Schultz, A. (1967). The Phenomenology of the Social World. Evanston, IL: Northwestern University Press.

Sherman, R. R., and R. B. Webb (1988). Qualitative research in education: A focus. In R. R. Sherman and R. B. Webb (eds.), Qualitative Research in Education: Focus and Methods, pp. 2-21. New York: The Falmer Press. 
Shulman, L. S. (1981). Disciplines of inquiry in education: An overview. Educational Researcher 10(6): 5-12, 23.

Smith, J. K. (1983a). Quantitative versus qualitative research: An attempt to clarify the issue. Educational Researcher 12(3): 6-13.

Smith, J. K. (1983b). Quantitative versus interpretive: The problem of conducting social inquiry. In E. House (ed.), Philosophy of Evaluation, pp. 27-52. San Francisco: Jossey-Bass Publishers.

Smith, J. K. (1984). The problem of criteria for judging interpretive inquiry. Educational Evaluation and Policy Analysis 6(4): 379-391.

Smith, J. K., and L. Heshusius (1986). Closing down the conversation: The end of the quantitative-qualitative debate among educational inquirers. Educational Researcher 15(1): 4-12.

Soltis, J. F. (1984). On the nature of educational research. Educational Researcher 13(10: 5-10.

Stanfield, J. H. (1985). The ethnocentric basis of social science knowledge production. In E. W. Gorden (ed.), Review of Research in Education, vol. 12, pp. 387-415. Washington, DC: American Educational Research Association.

Taylor, C. (1987). Interpretation and the science of man. In P. Rabinow and W. M. Sullivan (eds.), Interpretive Social Science. A Second Look, pp. 33-81. Berkeley, CA: University of California Press.

Tierney, W. G. (1991). Utilizing ethnographic interviews to enhance academic decision making. In D. M. Fetterman (ed.), Using Qualitative Methods in Institutional Research, pp. 7-22. San Francisco: Jossey-Bass, Publishers.

Urmson, J. O., and J. Ree (1989) (eds.). The Concise Encyclopedia of Western Philosophy and Philosophies. Boston: Unwin Hyman.

Yancey, B. D. (1988a). Exploratory data analysis methods for institutional researchers. In B. D. Yancey (ed.), Applying Statistics in Institutional Research, pp. 97-110. San Francisco: Jossey-Bass, Publishers.

Yancey, B. D. (1988b). Institutional research and the classical experimental paradigm. In B. D. Yancey (ed.), Applying Statistics in Institutional Research, pp. 5-10. San Francisco: Jossey-Bass, Publishers. 